\title{
Arte, conflicto, solución
}

Solución: es un concepto que surge de un conflicto , en la interrelación entre conflicto y solución ha tenido lugar el despliegue del saber humano. La solución fluye desde la ejecución y puesta en marcha de un procedimiento con miras hacia una verdad. Ahora bien, al comprender el conflicto como un estado en el que oscilan dos posibilidades adversas que alteran la proyección u horizonte de algún objetivo, tiene cabida el arte como una importante posibilidad que abre el camino a un sinnúmero de formas procedimentales, transversales y sensibles del ser humano sobre el mundo.

Así, desde la perspectiva de Joseph Beuys, por ejemplo, adviene la figura del chaman y su espiritualidad curativa, su intervención ritual por y sobre los conflictos; el curar se define como sinónimo de purificación, de selección y de evidencia de algo para su respectiva solución; en los saberes otros, enunciados desde la visión de algunos médicos tradicionales, sanar es cerrar heridas, borrar huellas por medio del saber, del sentir y del hacer; se trata de desvanecer ciertos conflictos que desarmonizan el el andar humano por el mundo.

En otros sentidos, con el advenimiento, durante las últimas dos décadas, de los medios digitales de comunicación masiva [Internet, telefonía celular, televisión digital, reproductores de música, video y fotografía, entre otros], el conflicto cotidiano que trastoca al ser humano día a día se va acrecentando, hasta tal punto que sus fronteras se disuelven en lo global; valga la pena resaltar que dicho progreso y valor totalizador del ser humano desplegado en la red nos unifica y constituye a la vez en un solo espacio virtual llamado red social, donde nuestros sentidos habituales se alteran, como si tuviéramos una nueva facultad. Así, con y por medio de esa nueva facultad corporal podemos sentir, pensar y ser entre lo colectivo y lo individual en espacios de encuentro virtual de la red mundial de información. Y es así como nos correponde habitar la premisa de "ser electrónicos", gozando de una virtualidad que nos acrisola en una nueva masa desde donde respondemos cada vez a nuevos conflictos.

Nuestra visión global del mundo asumida como un nuevo sentido, en todas las posibles dimensiones, nos trastoca y se encarna abriendo una gama de nuevos conflictos que nos retan para buscar nuevas soluciones.

Curar saberes difíciles, pone a nuestro autor invitado Aurelio Mesa [curador de arte] en un juego sensible del saber y el hacer en un campo adverso: por un lado el de ver hacer desaparecer a través de la violencia y por otro el de hacer aparecer por medio del dibujo el espacio ausente que nos dejan las más de 40 personas desaparecidas en Ayotzinapa. Una verdadera curaduría editorial, que sobrepone el rostro reconfigurado de cada uno de los muertos, seguido del análisis conceptual de dichas invocaciones por y sobre la muerte.

Ignacio Soneira, resalta la delgada línea entre el arte, la sociedad y la religión en una compilación de instalaciones visuales que no solamente aluden a objetos de arte, sino que desde sus principios estéticos permiten visualizar un ser humano totalizador, interdisciplinar, sensible, pensante, que encuentra en los objetos y su respectiva instalación verdaderos altares de conjuro 
frente a la estética de la muerte en planos que trascienden las fronteras de la representación figurativa para fijarse como valores humanos.

Sonia Natalia Cogollo, desde la perspectiva de algunos artistas reconocidos del país, como Juan Fernando Herrán y Clemencia Echeverri, nos presenta la fotografía como una herramienta clave para la narrativa visual de una violencia que ha implacable con Colombia. Desde una perspectiva distante a lo que hasta el momento configuramos como conflicto y arte y ubicándonos específicamente en la ciudad de Bogotá [Colombia], Aidaluz Sánchez, nos presenta un conflicto divergente que se sucede en el encuentro de "lo afro" en la práctica dancística y en su respectiva confrontación cultural.

Carlos Vásquez, por su parte, reflexiona acerca del conflicto entre la creación-investigación desde el ámbito de las artes escénicas, a partir de una presentación práctico-conceptual sobre de la creación del personaje realizada por el profesor Carlos Araque, donde se visualizan valiosos elementos teóricos acerca de la relación creación-investigación.

Jorge Peñuela, nos presenta el gesto interdisciplinar de la Universidad y el arte frente a la sociedad, en un performance colectivo, llevado a cabo en el Camino a San Moritz, como un lugar histórico en el que sucede una serie interesantísima de encuentros de público, artistas y teóricos en un contexto de prosaicas y cotidianidades de haceres y pensares.

Los escenarios teatrales y/o sociales donde habitamos cuerpo, son dos nuevos elementos que componen la indagación que ha venido llevando a cabo Carlos Araque, acerca del problema del teatro poshistórico, en una relación intrínseca del teatro y la sociedad.

En conversación a ello, Andrés Corredor, evidencia la importancia de la pintura de los Indígenas Colombianos en la construcción de una cultura universal incluyente, a partir de algunas "diferencias" enmarcadas, por ejemplo, en el ojo del indígena y su inferior percepción del color azul y verde y los respectivos modos de representación que ello implica, una interesante reflexión sobre los estudios culturales y la perspectiva cromática desde el ojo americano. Mónica Eraso, Emilo Tarazona y María Villate, desde una perspectiva crítica nos presentan la obra temprana de una de las artistas militantes cuyo trabajo aportó valiosos elementos para el arte y el movimiento social en Colombia durante los años 70, reflexionado acerca de lo que plantean como un cambio de enfoque.

Las reseñas de Sabrina Soledad Gil del libro, La Relación palabra / imagen en la cultura visual latinoamericana del siglo XX, de Mario Boido; y de la obra de Antonio Turok en el Museo Archivo de la Fotografía de Ciudad de México, escrita por Santiago Rueda; nos permiten cerrar este número que ponemos en manos de nuestros lectores. 

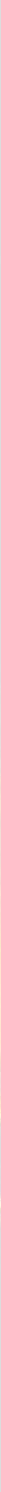

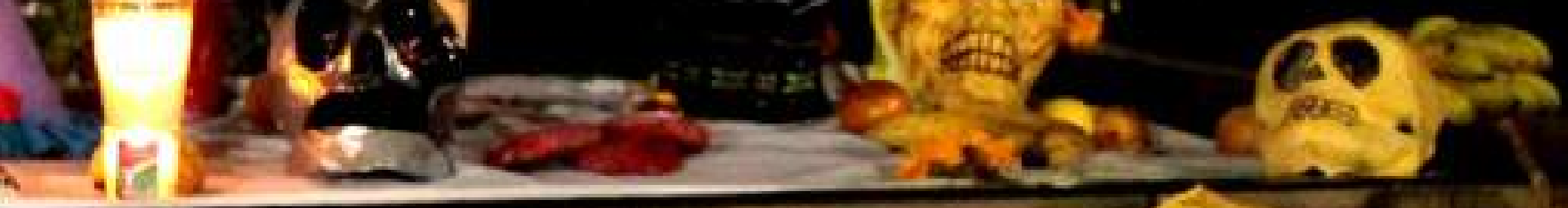

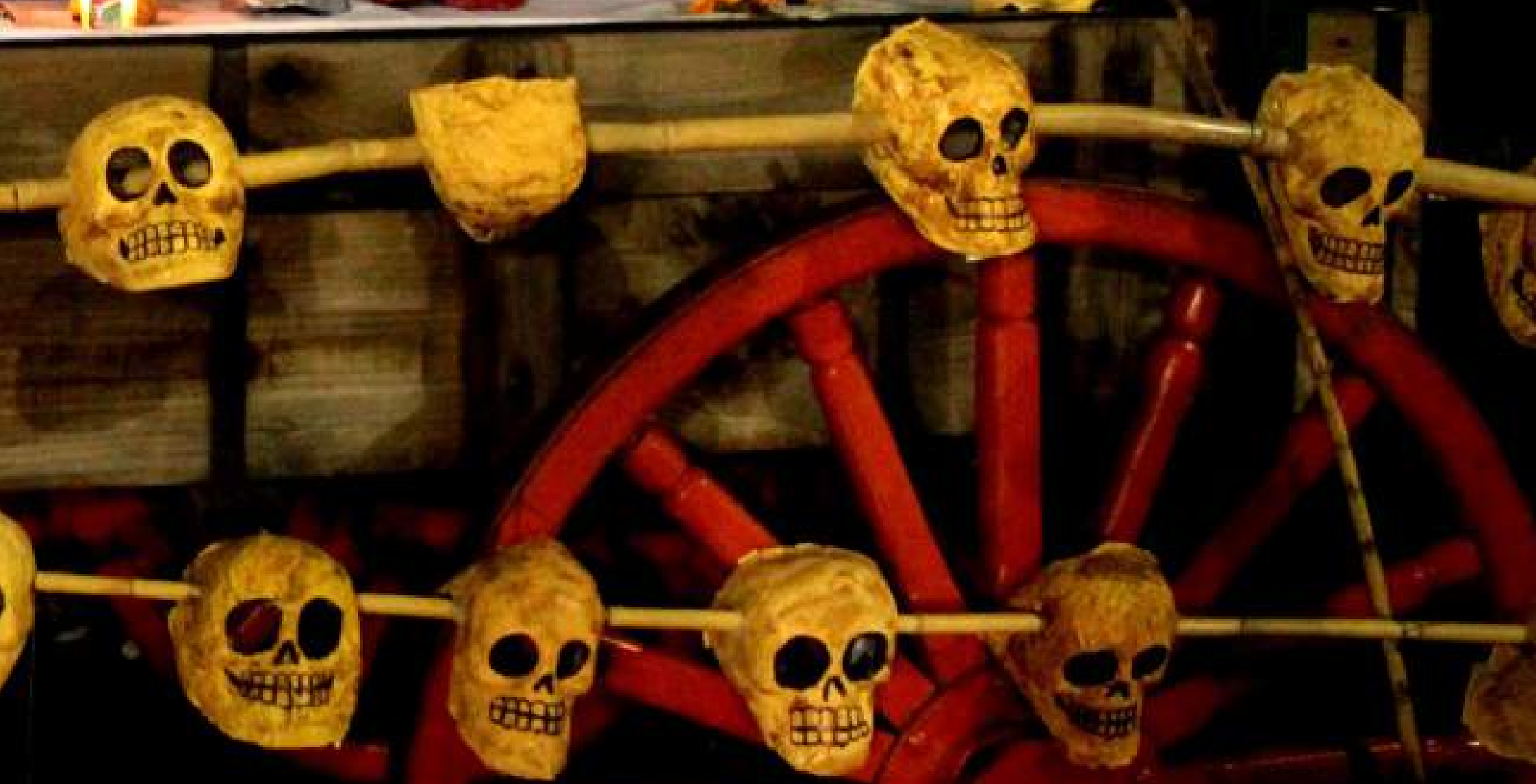

"Míxquic" Fotografía: Sonia Lucía Güiza, 2014. 